\title{
MORTALITY AMONGST BABIES FROM INJURY AT BIRTH
}

\author{
BY \\ W. T. RUSSELL and IAN SUTHERLAND \\ From the Institute of Social Medicine, Oxford
}

Much has been said and written about infant mortality and particularly about its decline. Even statesmen have cited its decrease as suggestive evidence of the benefits which arise from their stewardship. They are, it would seem, oblivious of the fact that the decline is not of recent occurrence but one which has been operating over a period of many years. The facts are easy to appreciate. Fifty years ago the mortality in infancy in England and Wales exceeded 150 per 1,000 births; in 1948 it was 34 , an impressive reduction which was particularly observable in the age group 3-12 months. The reduction in the first four weeks of life has been less satisfactory.

It may well be asked whether each contributory cause of death in early infancy has declined equally or whether some have declined more than others. If the average annual change in the mortality " under 4 weeks" during the period 1931-38 is expressed as a percentage of the mean death rate in that period in England and Wales, the statistical picture for certain broad categories is as in Table I.

It will be noted that in four instances the mortality has declined, the annual decrement being largest (9. 1 per cent.) for convulsions. The death rate in the two remaining groups, congenital malformations and injury at birth, increased, and the increment for the latter was the greater as the values were $1 \cdot 1$ per cent. and 2.6 per cent. respectively. It should be stated, however, that there is a school of expert medical opinion which regards such observed increments as fictitious. Although it recognizes the total neonatal mortality as a reliable figure, it suggests that the constituent causes defy statistical analysis owing to the inability of doctors in general to state, with any degree of precision, the exact cause of death at this period of life. The difficulties of accurate certification of causes of death in the first four weeks of life are well recognized, but it would seem unlikely that medical men are in the habit of exaggerating birth injury as a cause. Indeed, the joint report of the Royal College of Obstetricians and Gynaecologists and the British Paediatric Association (1949) has suggested a much higher rate of mortality from birth injury than is revealed by the Registrar General's tabulations.

It is not the province of a statistician to question the validity of medical diagnosis. In the absence of a sudden or startling departure from the normal mortality (apart from epidemic experience), he accepts the declared findings as facts although he is, at the same time, fully conscious of the vagaries of medical opinion and the influence of new precisions on diagnosis. We have been told, however, that the increments which have been demonstrated in the mortality from injury at birth may possibly be due to a transfer of deaths from asphyxia, atelectasis, or convulsions. The death rate from convulsions has declined, and convulsions in children under four weeks are believed, in many instances, to be the aftermath of an injury during delivery. As a test we calculated the mortality of a combined group of causes of death, namely convulsions, injury at birth, asphyxia, and atelectasis, over a

TABLE I

Average Annual Change in Mortality “Under Four Weeks"’ Expressed as Percentage of Mean Death Rate

\begin{tabular}{c|c|c|c|c|c|c}
\hline & Convulsions & $\begin{array}{c}\text { Congenital } \\
\text { malformation }\end{array}$ & $\begin{array}{c}\text { Congenital } \\
\text { debility }\end{array}$ & $\begin{array}{c}\text { Premature } \\
\text { birth }\end{array}$ & $\begin{array}{c}\text { Injury at } \\
\text { birth }\end{array}$ & Other causes \\
\hline $\begin{array}{c}\text { Mean death rate under 4 } \\
\text { weeks per 1,000 live births }\end{array}$ & 0.89 & $3 \cdot 65$ & $1 \cdot 52$ & 16.02 & $2 \cdot 30$ & $6 \cdot 28$ \\
\hline $\begin{array}{c}\text { Percentage annual increase or } \\
\text { decrease } . . \quad \cdots \quad . \quad .\end{array}$ & $-9 \cdot 1$ & $+1 \cdot 1$ & -6.7 & -1.9 & $+2 \cdot 6$ & $-1 \cdot 3$ \\
\hline
\end{tabular}


period of years. In 1945 approximately 4,000 deaths of babies under one month were ascribed to this causal group. If it can be shown that the mortality from this combination has increased, then there is little basis for suggesting that a transference of deaths affords an adequate explanation. The death rates at ages under four weeks per 1,000 births were as in Table II for (A) the combined group, and (B) the residual neo-natal mortality.

TABLE II

Death Rates Under four Weeks Per 1,000 Births A. COMbined

B. Residual

\begin{tabular}{c|c|c}
\hline Period & A & B \\
\hline $1921-30$ & $5 \cdot 03$ & $27 \cdot 53$ \\
$1931-39$ & $5 \cdot 20$ & $25 \cdot 48$ \\
1945 & $5 \cdot 55$ & $19 \cdot 21$ \\
\hline
\end{tabular}

It will be seen that the death rates in $(A)$ differ from those in (B) in their movement; if anything, they indicate a slight increase in their secular trend. In this connexion a comment by Martin is relevant:

A matter for concern is the steady rise in deaths due to injury at birth, from $1 \cdot 22$ in 1920 to 2.59 in 1938. A similar trend has been shown by the United States where the mortality from injury at birth rose from 3.9 in 1920 to a peak of 5.3 in 1930 and then declined slightly to $4 \cdot 8$ in 1939.

It is not possible to obtain an inclusive rate for the three causes of death in the main geographical regions of England and Wales over a long series of years, as deaths from asphyxia and atelectasis were not published separately for each area until 1940. Accordingly the combined rate for convulsions and injury at birth under four weeks was calculated and is set out in Table III.

TABLE III

Combined Death Rate for Convulsions and InJury AT BIRTH

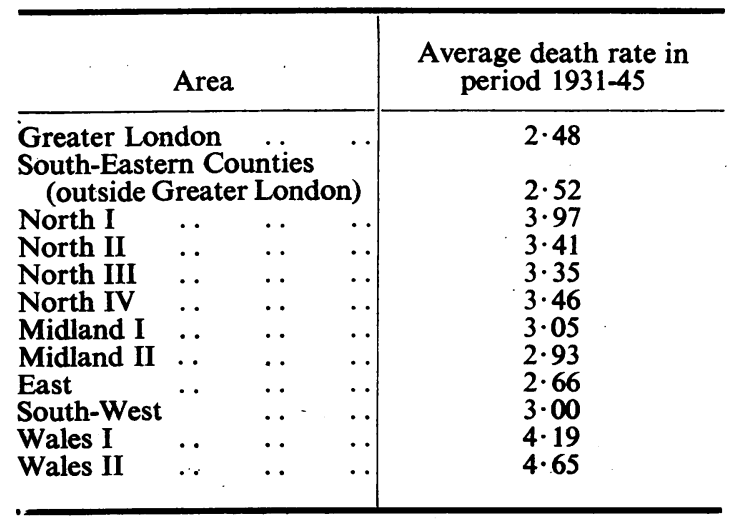

The following list enumerates the counties grouped in Tables III and XII:

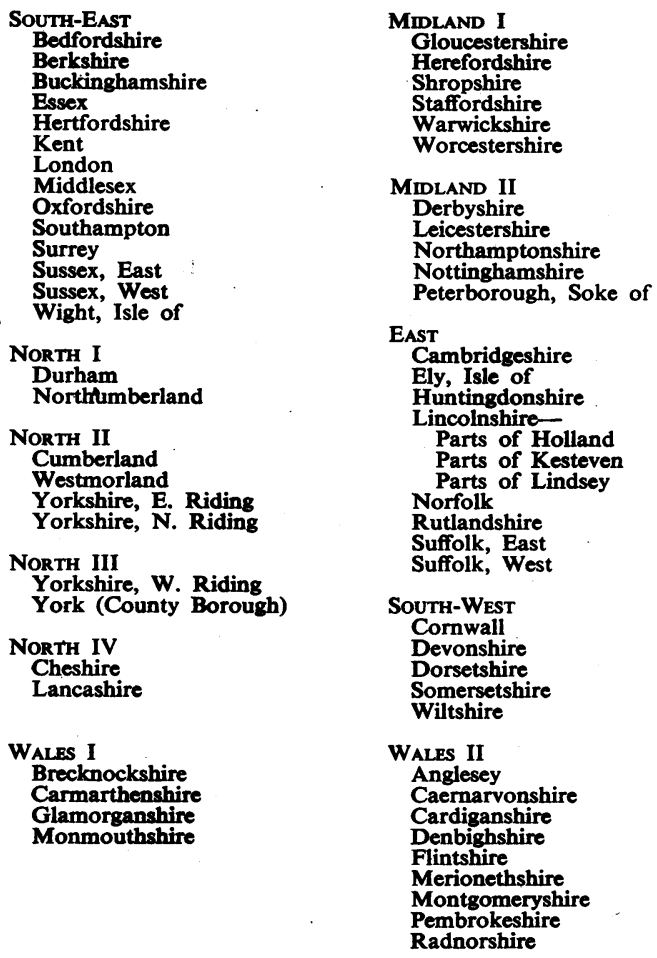

The lowest rate was 2.48 in Greater London, and the highest was 4.65 in Wales II (North Wales). The large geographical differences in Table III and the suggested increment in the mortality in recent years (Table II) would seemingly indicate that injury at birth is a problem meriting attention. The number of deaths ascribed to this specific cause is not unimportant, as in 1945 in England and Wales the deaths of 1,785 babies under four weeks were specifically ascribed to injury at birth. Furthermore, on page 33 of report No. 94* on Neo-Natal Mortality and Morbidity it is stated: "Most observers agree that one of the leading causes of death in the first four weeks of life is injury at birth." For this reason it seemed desirable to study the available statistics in the hope that some light might be shed on this aspect of the mortality of infancy. Such is the purpose of the present investigation.

\section{VARIation ' in Rates of Mortality}

In 1940 the Registrar General began the tabulation of deaths from injury at birth under one year in each administrative county and in each county borough

* Report by a joint committee of the Royal College of Obstetricians and Gynaecologists and the British Paediatric Association (1949). His Majesty's Stationery Office, London. 
TABLE IV

Mean Death Rate from InJury at Birth Under ONE YEAR

\begin{tabular}{l|c|c}
\hline Area & $\begin{array}{c}\text { Mean death rate } \\
\text { under 1 year per } \\
1,000 \text { births }\end{array}$ & $\begin{array}{c}\text { Coefficient of } \\
\text { variation }\end{array}$ \\
\hline $\begin{array}{l}\text { Administrative } \\
\text { counties }\end{array}$ & $2 \cdot 57$ & 21 \\
County boroughs & 2.63 & 30 \\
\hline
\end{tabular}

in England and Wales. Accordingly, it is possible to obtain a picture of the variation in the mortality throughout the country. The mean rate based on the statistical experience of 1940-43 with the inclusion of 1945 (the report for 1944 is not yet published) in areas with at least 5,000 live births during these five years and the relative percentage dispersion (coefficient of variation) around the mean rate (unweighted) were as in Table IV.

The death rate in the large towns is slightly greater than that in the administrative areas, and in both there is an appreciable dispersion in the mortality, the scatter (coefficient of variation) being relatively greater in the former than in the latter. The actual range in the mortality in the county boroughs was from 1.35 to $5 \cdot 74$ per 1,000 births and in the counties was from $1 \cdot 47$ to $3 \cdot 98$. Examples of high and low death rates per 1,000 live births are set out in Table V. counties (Reading and Oxford) is revealing (Table: VI).

\section{TABLE VI}

Death RATE UNDER ONe Year from INJURy at BIRTH aND Neo Natal Death Rate of OXFoRd aND Reading.

\begin{tabular}{l|c|c}
\hline Area & $\begin{array}{c}\text { Death rate under } \\
\text { 1 year from injury at } \\
\text { birth per 1,000 live } \\
\text { births }\end{array}$ & $\begin{array}{c}\text { Neo-natal death rate* } \\
\text { (excluding injury at } \\
\text { birth) per 1,000 live } \\
\text { births }\end{array}$ \\
\hline Oxford & $2 \cdot 68$ & $15 \cdot 0$ \\
Reading & $2 \cdot 18$ & $23 \cdot 2$ \\
\hline
\end{tabular}

* As it was not possible to obtain the death rate from injury at: birth for the age period 0-4 weeks for each administrative county, each county borough and each metropolitan borough, the rate from injury at birth at 0-12 months has been subtracted from the total injury at birth at $0-12$ months has been subtracted from the total neonatal mortality. This is a legitimate step, since over 95 per cent. of the total deaths from injury at birth in England and Wales occur
during the first four weeks of life. Hence it will be understood that in this paper the residual neonatal mortality equals the neonatal death rate from all causes minus the death rate from injury at birth at 0-12 months.

The death rate from injury at birth in Oxford is: 23 per cent. in excess of that in Reading, whereas the neonatal rate is 35 per cent. in defect. The explanation of the divergence may be that in Oxford there is more accurate reporting, due to the teaching and team work of the obstetrical unit at the Radcliffe. Infirmary; or that the social structure of the population of Oxford is, on the average, better than that of Reading and, as will be shown later, the mortality from injury at birth is correlated with

TABLE V

Mean Death Rate for Injury at Birth

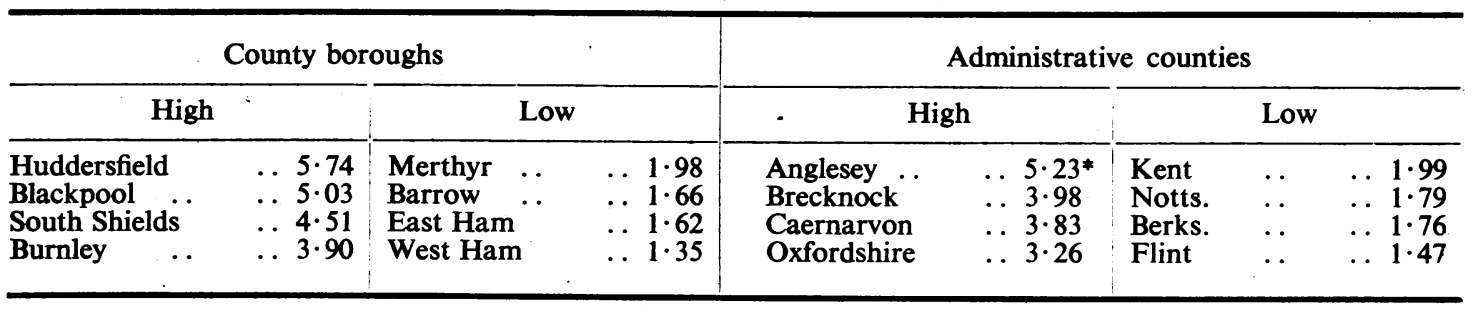

* Rate based on less than 5,000 births.

The towns reveal a striking contrast. East Ham and West Ham, overcrowded East London boroughs, are at the bottom of the list, and Huddersfield and Blackpool, two towns differing considerably in their social and occupational environment, are at the top. In the administrative counties an equally striking comparison is evident. Oxfordshire, which invariably has one of the lowest rates from infant mortality, has a rate from injury at birth nearly double that of the contiguous county of Berkshire. The contrast between the county boroughs in these two social class, the death rate being greater among the higher than among the lower social groups of the population in England and Wales.

\section{Geographical Distribution}

In view of the disparity revealed by the foregoing comparisons, it was of interest to obtain a picture of the statistical importance of the mortality in the geographical counties of England and Wales, the geographical county being the administrative county including its county borough. For this purpose it 
was deemed more satisfactory to compare the actual and calculated deaths, the " expected" or "calculated" deaths being deduced from the average statistical experience in the aggregated administrative counties and in the aggregated county boroughs respectively. An example will elucidate the procedure.

In the aggregated administrative counties of England and Wales the weighted average death rate under one year from injury at birth during the five years 1940-43 with the addition of $1945,{ }^{*}$ was 2.50 per 1,000 live births and in the aggregated county boroughs $2 \cdot 75$. Hence in the administrative county of Warwick, in which there were 38,508 live births during the period, the number of " expected " deaths from injury at birth would be

$$
\frac{38,508 \times 2 \cdot 50}{1,000}=96
$$

Similarly in the county borough of Warwick the expected number would be

$$
\frac{112,495 \times 2 \cdot 75}{1,000}=309
$$

Hence the calculated number of deaths from injury at birth in the geographical county would be

$$
96+309=405
$$

Finally the statistical significance of the difference between the actual and calculated number of expected deaths in each geggraphical county was estimated from the formula

$$
\frac{\text { Actual deaths-Expected deaths }}{\sqrt{\text { Expected deaths }}}
$$

and the results are depicted in Fig. 1 in which the shadings indicate counties with mortality significantly in excess, moderately in excess, moderately in defect, and significantly in defect. An example may help to facilitate its interpretation.

The difference in Warwickshire is positive, and,

* The figures for 1944 are not yet available. since it exceeds twice its standard error, it indicates an excessive number of deaths in this county. On similar reasoning the mortality in Berkshire is significantly in defect of what would be expected from the general average.

There is no definite belt or region of high mortality. The " black spots" are widely separated: Suffolk and Warwickshire in England; Pembroke, Caernarvon, Anglesey, and Denbigh in Wales. It is surprising to discover in Lancashire, where the infant mortality is invariably excessive, that the number of deaths from injury at birth is subnormal. The general picture in Fig. 1 certainly lacks the definition presented by Fig. 2, which relates to the disposition of the neonatal deaths excluding injury at birth. Here it will be observed that there are two distinct zones of excess and defect and the line of demarcation is from the Humber basin to that of the Severn. To the east of this line, including the counties of eastern and southern England generally, the mortality is low, whereas to the west and north the death rate is excessive. In view of this apparent dissimilarity in the geographical alignment of the two variables-injury at birth and the residual neonatal mortality-it was of interest to obtain a picture of the geographical distribution of the maternal mortality (Fig. 3). In it there are three black areas: one represented by Northumberland, Durham, and the North Riding of Yorkshire; the second, by Pembroke and Glamorgan; and the third, by Devonshire. In other respects the main features of this map are not unlike those outlined in Fig. 2.

A pictorial presentation based on the geographical county has an attraction, since it enables a quick impression to be gained, yet if one desires to make a precise comparison, the county as a unit may possibly be too large and so help to depress aspects inherent in the statistics of the large towns. For this reason it was resolved to evaluate the correlation coefficients between the three variables (1) injury at birth, (2) neonatal mortality (excluding injury at birth), and (3) maternal mortality in those county boroughs and administrative counties which had

\begin{tabular}{|c|c|c|c|c|}
\hline & Actual No. & Expected No. & Difference & $\begin{array}{c}\text { Standard error of } \\
\text { difference }\end{array}$ \\
\hline $\begin{array}{l}\text { Warwickshire } \\
\text { Berkshire }\end{array}$ & $\begin{array}{r}466 \\
57\end{array}$ & $\begin{array}{r}405 \\
78\end{array}$ & $\begin{array}{r}61 \\
-21\end{array}$ & $\begin{array}{r}3 \cdot 03 \\
-2 \cdot 38\end{array}$ \\
\hline
\end{tabular}
more than 5,000 births during the five years. Partial correlation coefficients were also calculated.

TABLE VII

DEATHS From INJURY at BirTh IN WARWICKSHIRE aND BERKSHIRE 


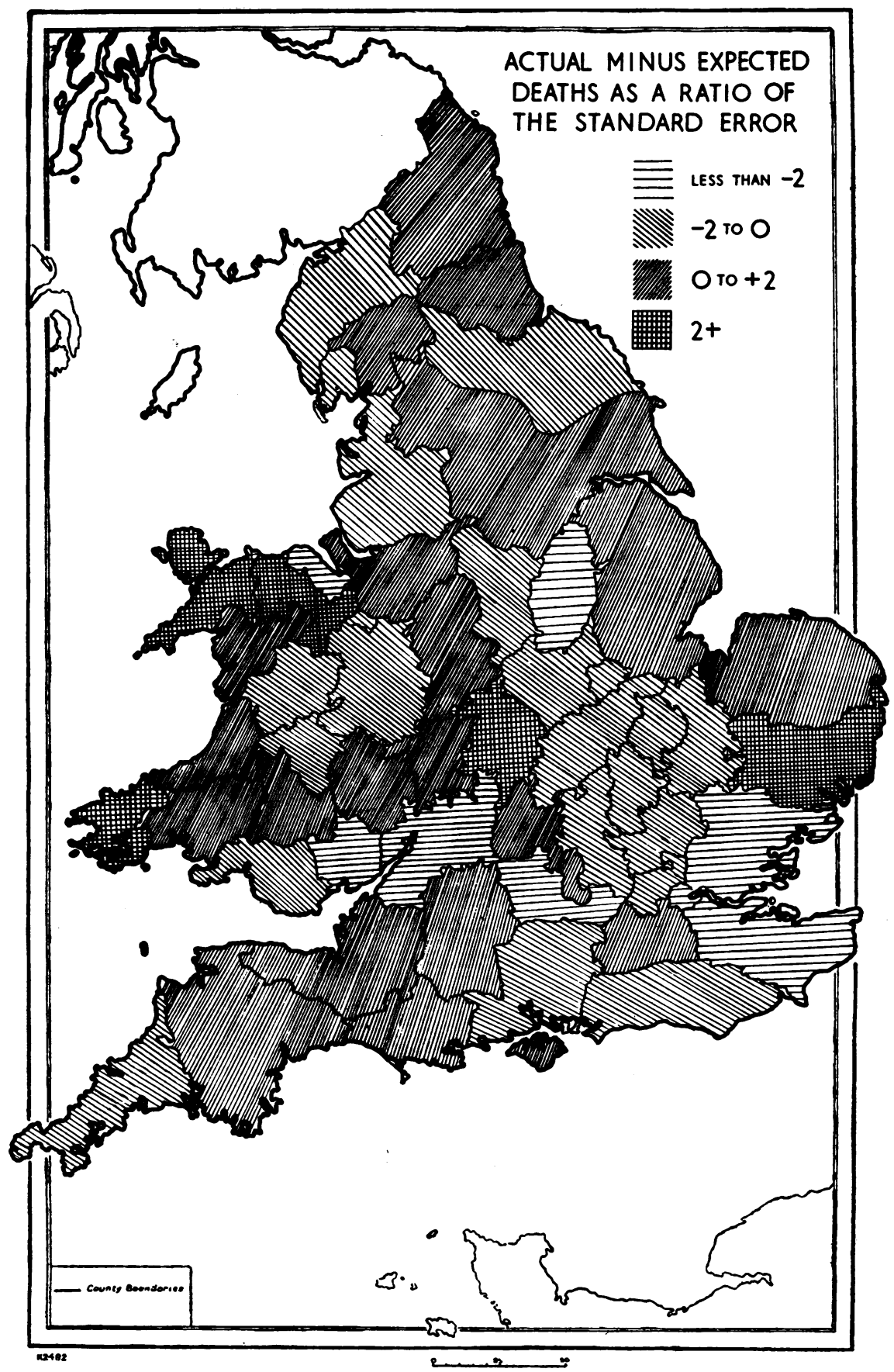

FIG. 1.-Map showing geographical incidence of injury at birth. 


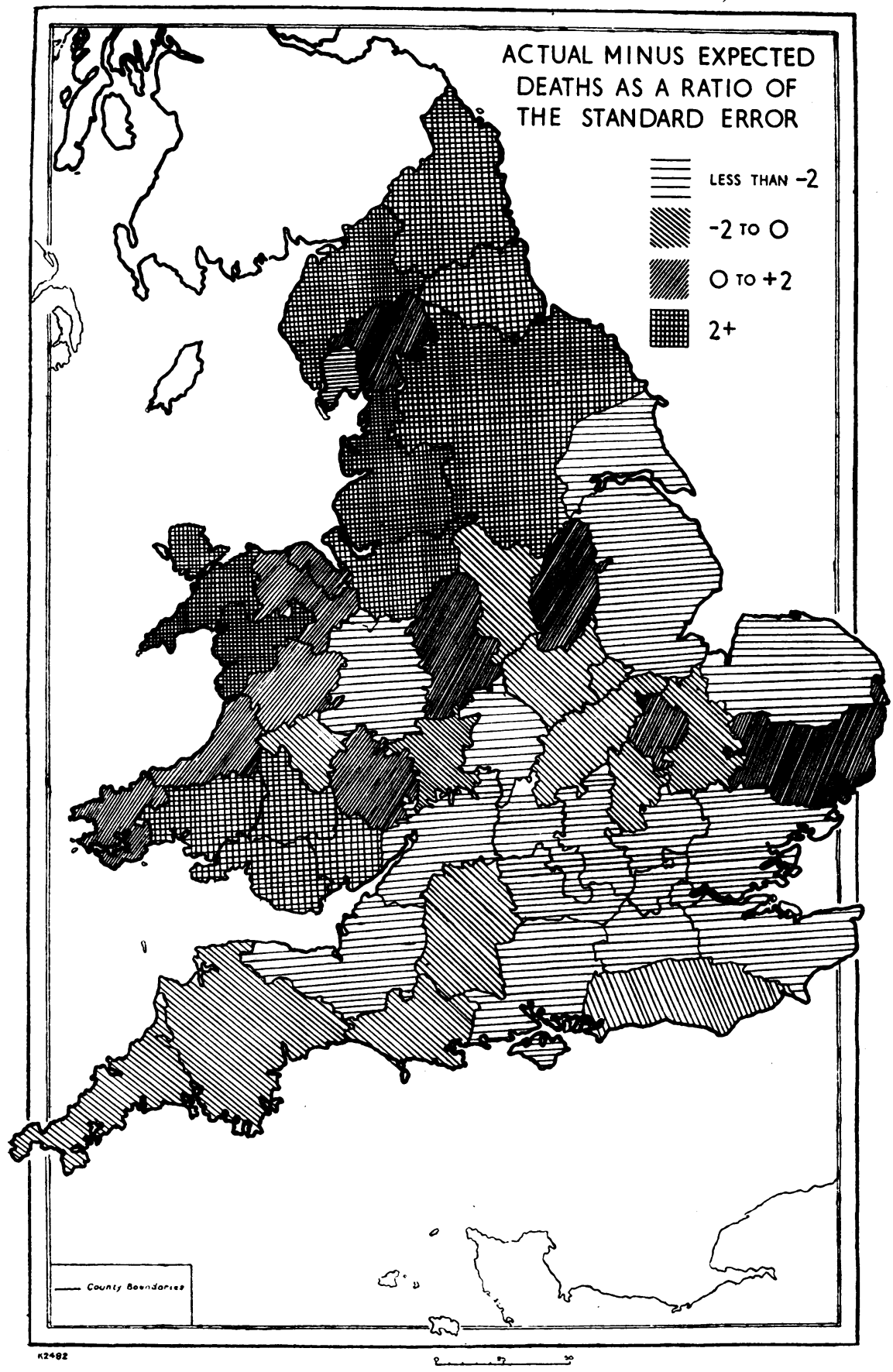

FIG. 2.-Map showing disposition of neonatal deaths excluding iniury at birth. 


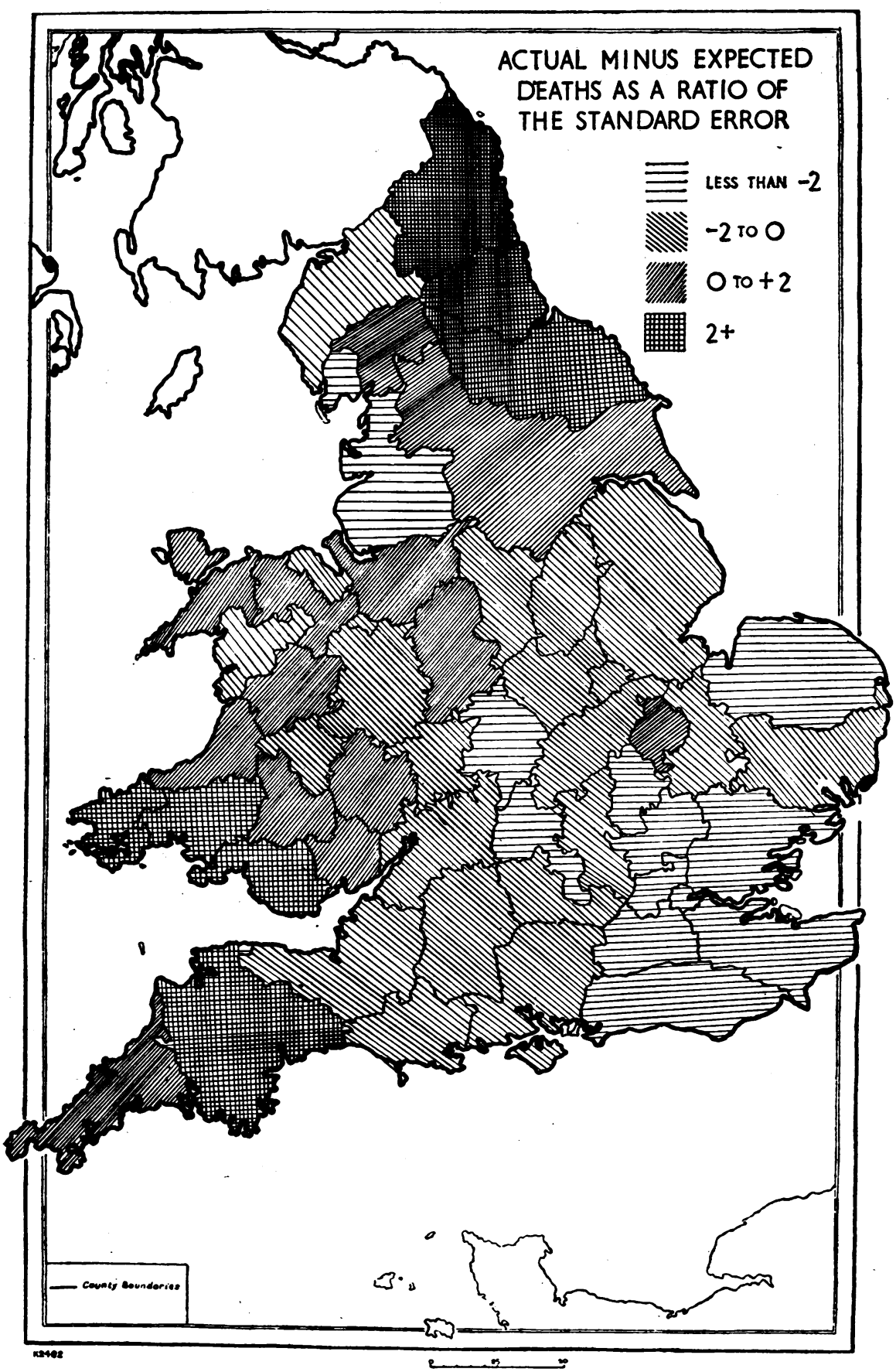

FIG. 3.-Map showing geographical distribution of maternal deaths. 
These measure the correlation between two of these variables when the effect of the third is eliminated. The results were as follows:-

$$
\begin{aligned}
& \text { Administrative counties }(52) \\
& \mathrm{r} 12=+\cdot 072 \quad \mathrm{r} 12 \cdot 3=-\cdot 014 \\
& \mathrm{r} 13=+\cdot 136 \\
& \mathrm{r} 23=+\cdot 614^{*}
\end{aligned}
$$

County boroughs (72)

$\mathrm{r} 12=+\cdot 233+\mathrm{r} 12 \cdot 3=+\cdot 193$

$\mathrm{r} 13=+\cdot 143 \mathrm{r} 13 \cdot 2=+.057$

$\mathrm{r} 23=+\cdot 399^{*} \mathrm{r} 23 \cdot 1=+\cdot 379 *$

* Statistically significant. † Borderline significance.

It will be noted that there is only a very small correlation between injury at birth and either the neonatal or maternal mortality. In other words, the factors which play a part in determining the mortality from injury at birth are relatively unimportant so far as the residual neonatal (dominated, of course, by prematurity) and maternal mortalities are concerned. On the other hand the correlation between the neonatal mortality and maternal mortality is substantial, particularly in the administrative counties, where the partial coefficient is $+\cdot 621$. Hence one can safely conclude that towns or administrative counties which have a high death rate from injury at birth do not necessarily have a proportionately high neonatal mortality.

\section{LONDON}

Since more births occur in hospital in London than in other parts of the country, a separate analysis was made for the 28 metropolitan boroughs. The correlation between the three variables was as follows:-

$$
\begin{array}{ll}
\mathrm{r} 12=+\cdot 266 & \mathrm{r} 12 \cdot 3=-\cdot 033 \\
\mathrm{r} 13=+\cdot 482^{*} & \mathrm{r} 13 \cdot 2=+\cdot 438 \dagger \\
\mathrm{r} 23=+\cdot 520^{*} & \mathrm{r} 23 \cdot 1=+\cdot 481^{*}
\end{array}
$$

* Statistically significant. † Borderline significance.

The results for the London boroughs confirm those in the county generally in as much as the partial coefficients indicate the dissociation between the mortality from injury at birth and the neonatal death rate; and the positive relationship between neonatal and maternal mortality.

They differ, however, in one aspect, because there is evidence that there is a fairly definite relationship between injury at birth and maternal mortality, the partial coefficient being $+\cdot 438$. What is the explanation of this ? Can it be that there is more surgical interference in deliveries in hospital, or is it simply that a high proportion of difficult cases are delivered in hospitals ?

\section{Possible Causes}

In view of the suggested increase in the mortality? from injury at birth in England and Wales generally $\vec{F}$ since 1921 , it is cogent to consider the possible $\frac{\text { के }}{0}$ causes under three headings.

An Increasing Proportion of First Births.-These $\frac{\bar{\sigma}}{\bar{D}}$ are generally accepted as being more difficult than $\frac{\vec{\phi}}{\overrightarrow{0}}$ subsequent deliveries. If this is so there should be $\varrho$ a positive correlation between the rate from injury at birth in an area and the proportion of first births $\overrightarrow{0}$ there. It is possible to obtain a crude answer on this aspect because the Registrar General has $\vec{\omega}$ published data showing the proportion of first? births in the 12 major divisions of England and $\stackrel{\Phi}{\frac{1}{3}}$ Wales. Correlating these ratios for the period $\omega$ 1940-42 with the corresponding death rates from 10 injury at birth, the coefficient was found to be $r=-0 \cdot 201$, a result which is statistically insignificant. 을

Significance of Hospital Deliveries.-In London, approximately 80 per cent. of the total births occur $D$ in institutions, as compared with approximately 20 per cent. in the remainder of the country. The $\vec{\oplus}$ corresponding rates of mortality from injury at $\frac{8}{0}$ birth are 2.48 and 2.56 per 1,000 births respectively. In view of the disparity in the proportion of births which occur in hospitals in London compared with the rest of the country and the approximate equality $\overline{0}$ in the rates of mortality (assuming that the data are 0 comparable in all other respects) it would seem that $\varnothing$ birth in hospital is an ineffective factor in preventing $\overrightarrow{\vec{O}}$ death from injury at birth. It may, of course, as 3 has been suggested, be argued that the more difficult cases are now usually removed to hospital for? delivery. It is perfectly true that difficult cases are $\frac{\bar{C}}{}$ referred to doctors by midwives but, as regards $\frac{\rho}{5}$ delivery in hospital in London the greater part of the enrolment is made early in pregnancy before a. prognosis is possible, excepting in so far as anatomi- $\delta$ cal abnormalities in the mother are recognizable in a proportion of cases.

Instrumental Delivery. -There has been an increas- $\rightarrow$ ing tendency in recent years to have recourse to으․ instrumental delivery. There are no specific n statistics to support this statement, but the contrast of the mortality rates according to social status may act as a pointer.

According to the statistics compiled for the periodo 1930-32 by the Registrar General, the death rateo from injury at birth and the residual neonatal mortality in three broad social groups in England $\stackrel{\odot}{+}$ and Wales in the period $1930-32$ was as set out in Table VIII.

It will be noticed that with descent in the social $\stackrel{\Phi}{\circ}$ scale the mortality from injury declines, whereas $\mathbb{Q}$ for the residual neonatal mortality there is ano 
TABLE VIII

Comparison of Death Rate from Injury at Birth and Residual NeONatal Mortality IN Three SOCIAL Groups

\begin{tabular}{c|c|c}
\hline \multirow{2}{*}{ Classes } & \multicolumn{2}{|c}{ Legitimate births } \\
\cline { 2 - 3 } & $\begin{array}{c}\text { Injury at birth } \\
\text { under 1 year per } \\
1,000 \text { live births }\end{array}$ & $\begin{array}{c}\text { Neo-natal mortal- } \\
\text { ity (excluding } \\
\text { injury at birth) } \\
\text { per 1,000 births }\end{array}$ \\
\hline $\begin{array}{l}\text { I and II (profes- } \\
\text { sional and ad- } \\
\text { ministrative } \\
\text { grades) }\end{array}$ & $2 \cdot 44$ & 23.9 \\
$\begin{array}{l}\text { III (skilled work- } \\
\text { ers) .. }\end{array}$ & $2 \cdot 13$ & $27 \cdot 3$ \\
$\begin{array}{l}\text { IV and V (semi- } \\
\text { skilled and un- } \\
\text { skilled labour- } \\
\text { ers) }\end{array}$ & 1.96 & 30.3 \\
\hline
\end{tabular}

increase. Obviously different agencies operate to produce this divergency.

Further evidence of the pattern made by social class is revealed by the statistics of a more recent date. When the boroughs of London are classified into two broad groups according to socio-economic status "good" and "poor", and the expected number of deaths is calculated for the quinquennial period 1940-43 (including 1945) and compared with those actually enumerated, the following results are obtained (Table IX).

TABLE IX

Actual and Expected Deaths from Injury at BIRTH IN LONDON BOROUGHS

Grouped According to Socio-Economic Status

\begin{tabular}{|c|c|c|c|}
\hline \multirow{2}{*}{ District } & \multicolumn{2}{|c|}{ Injury at birth } & Difference \\
\hline & Actual & Expected & Standard error of difference \\
\hline $\begin{array}{l}\text { Good } . . \\
\text { Poor } . .\end{array}$ & $\begin{array}{l}319 \\
204\end{array}$ & $\begin{array}{l}306 \\
221\end{array}$ & $\begin{array}{r}+0.74 \\
+0.15\end{array}$ \\
\hline
\end{tabular}

It will be seen that there is a tendency for the "good districts" to have a mortality in excess of the average and for the "poor" areas to be in defect, although in neither instance is the difference statistically significant. The picture, while it is suggestive, is not as definite as is that for maternal mortality in the two groups (Table X).

In the "good" districts the recorded maternal deaths are significantly in excess of the number expected to occur, whereas in the poor areas they are statistically below expectation. It may be argued that the correlation which has been indicated
TABLE $X$

Actual and Expected Maternal Deaths in London Boroughs Grouped ACCORDING TO SOCIO-ECONOMIC STATUS

\begin{tabular}{|c|c|c|c|}
\hline \multirow{2}{*}{ District } & \multirow{2}{*}{ Actual } & \multirow{2}{*}{ Expected } & Difference \\
\hline & & & Standard error of difference \\
\hline $\begin{array}{l}\text { Good } \\
\text { Poor }\end{array}$ & $\begin{array}{l}295 \\
158\end{array}$ & $\begin{array}{l}261 \\
192\end{array}$ & $\begin{array}{l}+2 \cdot 10 \\
-2 \cdot 45\end{array}$ \\
\hline
\end{tabular}

may possibly be due to a higher proportion of first births in the better class districts but this argument invites the question, Is injury at birth relatively more frequent amongst first births ? The available statistical evidence based on the Registrar General's returns, to which reference has already been made, offers no confirmation of this idea. The correlation coefficient between injury at birth and the proportion of first births was statistically insignificant.

\section{Age of Mother}

Since age is an important correlate of mortality statistics it may be asked to what extent the age of the mother is a dominant factor in the present instance. Is injury to the baby at birth relatively more frequent among older than younger mothers, particularly if they are primiparous women? The only available evidence on this aspect of the problem on a national scale was that relating to stillbirths in Scotland during the years 1939-45. The death rate ascribed to injury at birth among the babies in this series of observations when correlated with the age of the mother was found to be as recorded in Table XI.

TABLE XI

Death Rate in Scotland from Injury at Birth in Stillbirths Classified According to Age of Mother

\begin{tabular}{|c|c|c|}
\hline \multicolumn{2}{|c|}{ Age of mother } & $\begin{array}{l}\text { Still-births per } 100,000 \\
\text { (live and stillbirths) }\end{array}$ \\
\hline $\begin{array}{l}\text { Under } 35 \text { years } \\
\text { Over } 35 \text { years }\end{array}$ & $\begin{array}{l}\cdots \\
\ldots\end{array}$ & $\begin{array}{r}90 \\
112 \\
\end{array}$ \\
\hline
\end{tabular}

It would appear from these values that the age of the mother is a factor of importance. This association invites the question, Has there been an increase in the age of motherhood ? Unfortunately the relevant statistics are only available for a restricted period, because it was not until 1939 that the statistics of births in relation to the age of mothers were first published in England and Wales. Comparing the mean age of legitimate maternities for first children in 1939 and in 1945 the values in the 12 major divisions were as in Table XII. 
TABLE XII

Mean age of Legrtimate Maternities in Twelve Major Divisions of England and Wales

\begin{tabular}{|c|c|c|c|}
\hline \multirow[t]{2}{*}{ Area* } & \multicolumn{2}{|c|}{$\begin{array}{l}\text { Mean age of legitimate } \\
\text { maternities (first } \\
\text { children) }\end{array}$} & \multirow[t]{2}{*}{ Difference } \\
\hline & 1939 & 1945 & \\
\hline \multirow{12}{*}{ 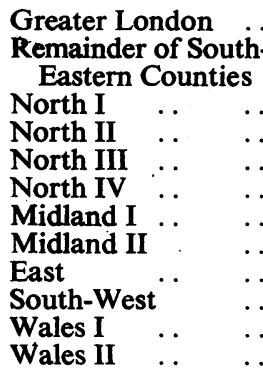 } & $26 \cdot 8$ & $26 \cdot 9$ & $+0 \cdot 1$ \\
\hline & $26 \cdot 4$ & $26 \cdot 5$ & $+0 \cdot 1$ \\
\hline & $25 \cdot 6$ & $25 \cdot 8$ & +0.2 \\
\hline & $25 \cdot 9$ & $26 \cdot 1$ & $+0 . \overline{2}$ \\
\hline & $26 \cdot 2$ & $26 \cdot 3$ & +0.1 \\
\hline & $26 \cdot 6$ & $26 \cdot 7$ & +0.1 \\
\hline & $26 \cdot 3$ & $26 \cdot 5$ & +0.2 \\
\hline & $26 \cdot 3$ & $26 \cdot 2$ & -0.1 \\
\hline & $26 \cdot 0$ & $26 \cdot 0$ & - \\
\hline & $26 \cdot 5$ & $26 \cdot 4$ & -0.1 \\
\hline & $25 \cdot 6$ & $25 \cdot 8$ & $+0 \cdot 2$ \\
\hline & 26. & $26 \cdot 9$ & \\
\hline
\end{tabular}

* See Table III for details of areas thus grouped.

It will be seen that in the majority of instances there has been an increase in the mean age, but it is not of sufficient moment to explain the ostensible increase in the mortality from injury at birth. Furthermore, the mean age of mothers in Greater London is almost identical with that of Wales II (North Wales). There is, however, a wide difference in the mortality rates from injury at birth, as is indicated by the composite figures presented in Table III.

\section{Summary AND CONCLUSIONS}

In this study we have considered only fatal injuries at birth, as no data are available in connexion with the numerous residual disabilities resulting from non-fatal injury. This analysis of the available statistics in England and Wales since 1921, and in various administrative counties and county boroughs including London, may be summarized as follows.
There has been an apparent increase in the mortality during the period 1921-45 even when allowance is made for the transference of deaths from convulsions, asphyxia, and atelectasis.

There are large differences between the mortality rates in the various administrative counties, and likewise between the county boroughs.

Contrary to expectation, there is little correlation between the mortality from injury at birth and the proportion of first births in the 12 major regions of England and Wales.

There is evidence from Scottish data on stillbirths that the mortality ascribed to injury at birth among them depended upon the age of the mother, the death rate being higher amongst older women. There are no available statistics in England and Wales which relate the age of the mother to the mortality from injury at birth. Statistics of the age of maternity have been published since 1939 and have indicated a slight increase in the mean age between 1939 and 1945 throughout the country. It is very doubtful, however, if this increase is sufficient to account for the suggested increase in the mortality.

The mortality in a group of " poor" boroughs in London is subnormal, whereas in a "residential" group it is in excess of the average for London. There is also a positive correlation between the mortality from injury at birth and the maternal death rate. This may or may not be the result of undue surgical interference.

The evidence presented would seem to indicate the reality of the problem, but complete proof of its existence, and, if it does exist, of its solution, can be determined only by a carefully planned specific study.

The need here demonstrated for such a study has recently been emphasized in the following statement from the Report on Neonatal Mortality and Morbidity.

“Many cases of birth injury are undoubtedly due to lack of obstetrical . skill and judgement on the part of the accoucheur, especially when delivery by breech or by forceps has been necessary.' 